\title{
The Use of Geogrids in Mitigating Pavement Defects on Roads Built over Expansive Soils
}

\author{
Richard Shumbusho $^{1^{*}}$, Gurmel S. Ghataora ${ }^{1}$, Michael P.N. Burrow1 ${ }^{1}$, and Digne R. Rwabuhungu ${ }^{2}$ \\ ${ }^{1}$ University of Birmingham, B15 2TT, Birmingham, UK \\ ${ }^{2}$ University of Rwanda, P.O. Box 3900, Kigali, Rwanda \\ *Corresponding Author: RXS383@bham.ac.uk \\ DOI: $10.4314 /$ rjeste.v4i1.4 \\ https://dx.doi.org/10.4314/rjeste.v4i1.4
}

\begin{abstract}
This study was conducted to investigate the potential benefits of using geogrids in mitigating pavement defects notably roughness and longitudinal cracking on pavements built over expansive soils. The seasonal changes of expansive soils (periodic wetting and drying) cause detrimental effects on the overlying road pavements. Such detrimental behavior of expansive soils was simulated in a controlled laboratory environment through allowing cyclic wetting and drying of an expansive soil underlying a pavement section. The shrink/swell effects of the expansive soil subgrade were examined through monitoring its change in moisture, and measuring deformation of overlying pavement section. The experimental study suggested that a geogrid layer in a reinforced pavement section can reduce surface differential shrinking and swelling deformation resulting from underlying expansive soils by a factor of 2 and 3 respectively in comparison to unreinforced section. Given that an oedometer test which is typically used to predict swelling potential of expansive soils is known to overpredict in-situ soil swell, experimental program also investigated quantitatively the extent to which the oedometer can overestimate swelling behaviour of the real-field scenarios. It was found that oedometer percent swell can overpredict in-situ swelling behaviour of the expansive soil by a factor ranging between 2 and 10 depending upon the period over which the in-situ expansive soil has been in contact with water.
\end{abstract}

Keywords: expansive soil, oedometer, longitudinal cracking, pavement, roughness 


\section{Introduction}

Expansive soils are well known for their shrink/swell behaviour associated with change in moisture content. Their shrink and swell can cause damages to overlying structures. The cost of damages caused by expansive soils is estimated in billions of dollars annually. For instance Jones and Jefferson (2012) reported that the cost of those damages to infrastructures in the US alone exceeds 15 billion US dollars yearly. The expansive soils are responsible for more damages to civil engineering structures (especially road infrastructure and low-rise buildings) than any other geohazards including floods and earthquakes (Mokhtari and Dehghani, 2012). The shrink/swell properties of expansive soils were unknown to civil engineers, and have been misjudged as settlement issues or poor construction techniques until late 1930s when the US Bureau of Reclamation first acknowledged them (Chen, 1975).

The expansive soils can be encountered in many places around the world particularly in arid and semi-arid regions (Tripathy et al., 2002). Much was done to address expansive soil problems; for instance between mid-1960s and early 1990s, there have been seven international conferences on expansive soils and numerous researches thereof were carried out (Petry and Little, 2002). In general, the previous researches included mostly chemical stabilization (mainly lime and cement), digging out expansive soils and replacing them with non-expansive soils, compaction control, prewetting, use of geomembranes, and moisture control measures (Jeyapalan et al., 1981; Nelson and Miller, 1992). More recently, geogrids were also used to mitigate environmental effects of expansive soil subgrades on overlying pavements (Luo and Prozzi, 2009; Sebesta, 2002; Zornberg and Gupta, 2009).

The wetting and drying of the expansive soil subgrade underlying road pavements are responsible for two major distresses which are roughness and longitudinal cracking (Picornell and Lytton, 1987). The most common distress that occurs on pavements built over expansive soils is longitudinal cracking (Luo and Prozzi, 2010; Wanyan et al., 2010). These longitudinal cracks are due to the tensile stresses developed from shrinking of expansive soils during dry seasons (Dessouky, 2015). Due to the fact that the subgrade is covered by the pavement, there is little or no evapotranspiration beneath the centerline of the pavement and the corresponding water content 
remains approximately constant. However, the area in the vicinity of pavement shoulders experiences moisture loss during dry periods and develops longitudinal shrinkage cracks. On the other hand, during wet seasons, there is moisture ingress in the vicinity of pavement shoulders, resulting in heave in this area (Nelson and Miller, 1992; Zornberg and Gupta, 2009). Shrubs and trees in the vicinity of pavement shoulders can aggravate the problem of longitudinal cracks as roots can absorb water from beneath pavement edges when a tree is planted in their close proximity (Sebesta, 2002; Scullion et al., 2003; Puppala et al., 2011).

The mechanism of the longitudinal cracks development has not been sufficiently addressed and their propagation process has not yet been clarified (Luo and Prozzi, 2010). It is important to elucidate the difference between longitudinal cracks resulting from shrinking of soil subgrades and longitudinal cracks resulting from pavement fatigue. Sebesta (2002) indicated that longitudinal cracking found in the wheel path are load-related and they are early signs of pavement fatigue. On the other hand, he showed that non-load related cracks found near pavement edges in the expansive soils area are due to shrinking of plastic clays and these fall within the scope of this study. Typical longitudinal cracks are shown in Figure 1.

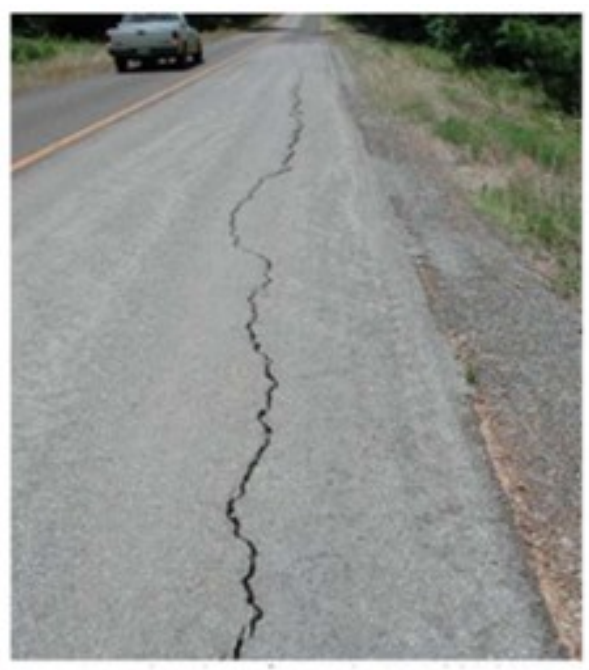

a) Sebesta (2002)

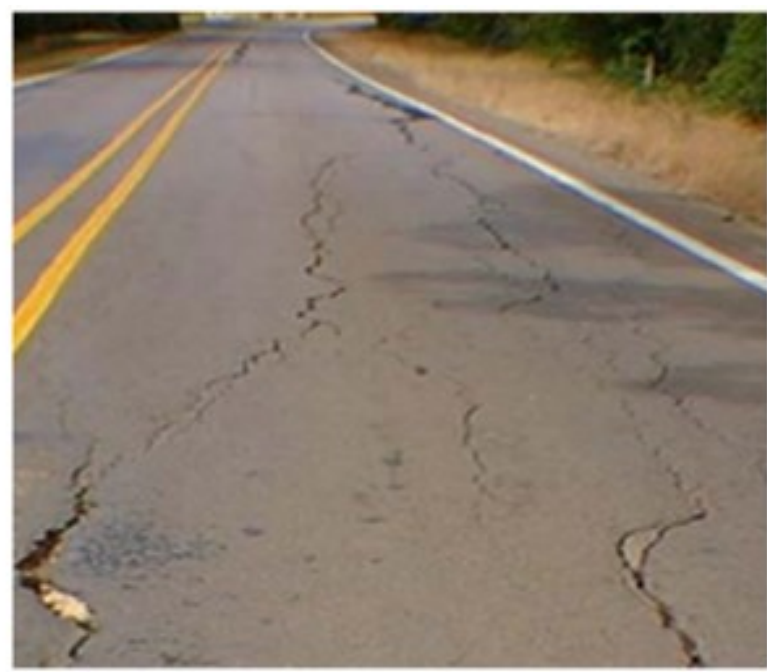

b) Scullion et al. (2003)

Figure 1 Typical longitudinal cracks found on road pavements built over expansive soils

The experience has shown that building thicker and stronger pavement layers over expansive soil subgrades does not guarantee better performance especially in high plasticity clays (Wanyan et al., 
2010). However, the use of geogrids in design was proven to be effective (Luo and Prozzi 2009, Zornberg and Gupta, 2009). The performance of geogrid-reinforced low volume road sections in terms of mitigating longitudinal cracking was found to be promising but the mechanism governing their performance has not been clearly understood (Zornberg et al., 2012). The use of geogrids to mitigate defects developed on road pavements built over expansive soils has not been fully investigated. The review of literature showed that this area of research is still at its infancy and previous researches conducted before the year 2000 did not generally consider geogrids in designing pavements over expansive soils (Shumbusho et al., 2018). This study aims to investigate experimentally the effects of geogrids in alleviating pavement defects on roads built over expansive soils.

\section{Methodology}

The seasonal changes of expansive soils (periodic wetting and drying) cause detrimental effects on the overlying road pavements. Such detrimental behavior of expansive soils can be better addressed through investigating their cyclic shrink/swell pattern and its effect on overlying pavements in a controlled laboratory environment. Shumbusho et al. (2020) conducted an in-depth study which presented the approximate current state of knowledge on the cyclic swell/shrink behaviour of expansive soils. It was found that the previous studies on cyclic shrink/swell of expansive soils used soil specimens of relatively small sizes (typical for conventional laboratory oedometer tests) which may not necessarily reflect the real field conditions. Laboratory oedometer tests are also known to overpredict swell of expansive soils (Lytton et al., 2004). This study sought to utilise soil specimens of relatively larger size, and to simulate the real field conditions (at least to some extent) of a road overlying an expansive soil subgrade. The experimental program also investigated quantitatively the extent to which oedometer swelling data of an expansive soil overestimates the swelling behaviour of the larger scale test scenarios.

\subsection{Physical model}

The laboratory pavement model consists of a half of isolated pavement test section overlying expansive soil in a steel tank with dimensions of $35 \mathrm{~cm} \mathrm{x} 45 \mathrm{~cm}$ x $45 \mathrm{~cm}$ as shown in Figure 2. Dry season was simulated using infrared heater of $2 \mathrm{~kW}$ capacity that offers temperature of over $40^{\circ} \mathrm{C}$, comparable to a very hot summer day in dry climates. The wet season was simulated by 
watering pavement edges through vertical perforated wall tank. As the isolated pavement test section extends from pavement edge to the assumed longitudinal centerline (simulating half of the road structure as shown in Figure 2), most of physical processes of wetting and drying lessen towards the centerline since it is covered, and thus less prone to water infiltration and evaporation. The wetting up of the subgrade through capillary rise was also considered where water with constant head of $1.45 \mathrm{~m}$ was supplied from the perforated tank base. A non-woven geotextile was placed at interface between soil and tank base for filtration. Two 5TM temperature \& moisture sensors, and two Linear Variable Differential Transducers (LVDTs) were installed on the pavement section to monitor change in physical parameters throughout testing process. The laboratory tests on the pavement sections were monitored for a period of 3 months; 35 and 50 days simulating dry and wet period respectively.

Two moisture sensors were installed as shown in Figure. 2, and they helped to monitor changes in moisture content within pavement structure. Given that the 5TM moisture sensors were designed to monitor water content of the soil within $5 \mathrm{~cm}$ distance from either side of the probe, they were placed at a depth of $5 \mathrm{~cm}$ below base-subgrade interface to be able to monitor its change in moisture content. Details about moisture sensors used and calibration process are presented in section 2.3.4. To be able to monitor the deformation of pavement surface resulting from shrinking and swelling of underlying expansive soil subgrade, two LVDTs (with 0-25 mm range and $\pm 0.1 \%$ accuracy) were installed transversally across the middle of pavement section. Given the anisotropy expected in transversal direction from pavement edges towards pavement centerline, the LVDTs were expected to show the variation in surface deformation with respect to the distance from pavement edges. The LVDTs were connected to a data logger that was also connected to a computer. The computer used $1232 \mathrm{HS}$ communications program software to communicate with the data logger. The data logger was set to record deformation data every 30 minutes. Before being used, the LVDTs were first calibrated using Vernier caliper and 1232HS communications program software. Figure 3 illustrates the entire set up when test is running simulating drying period. 


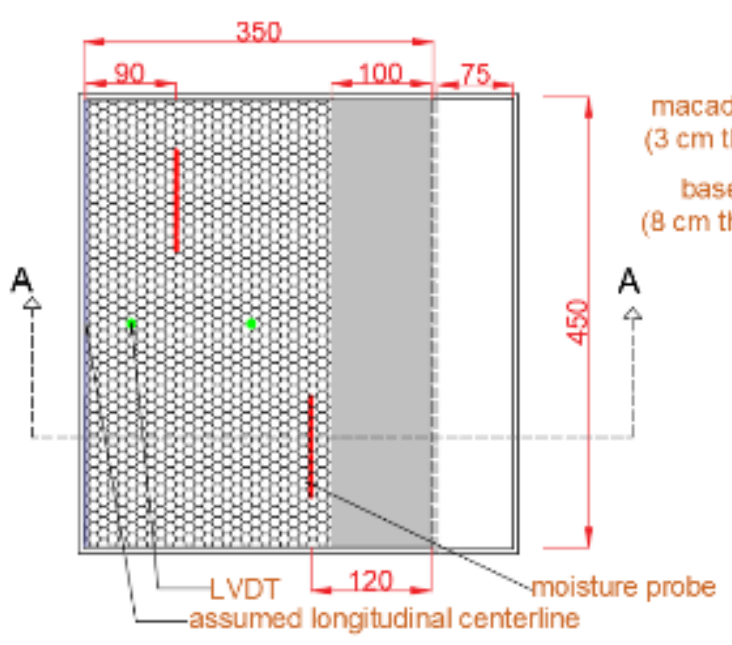

PLAN

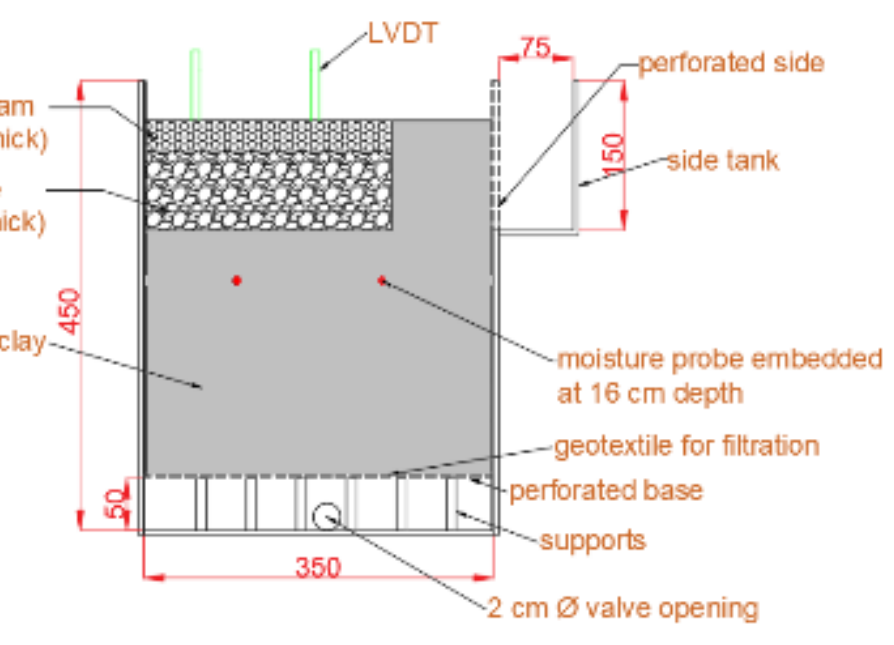

Section AA

Figure 2 Schematic diagram of unreinforced test section and its instrumentation

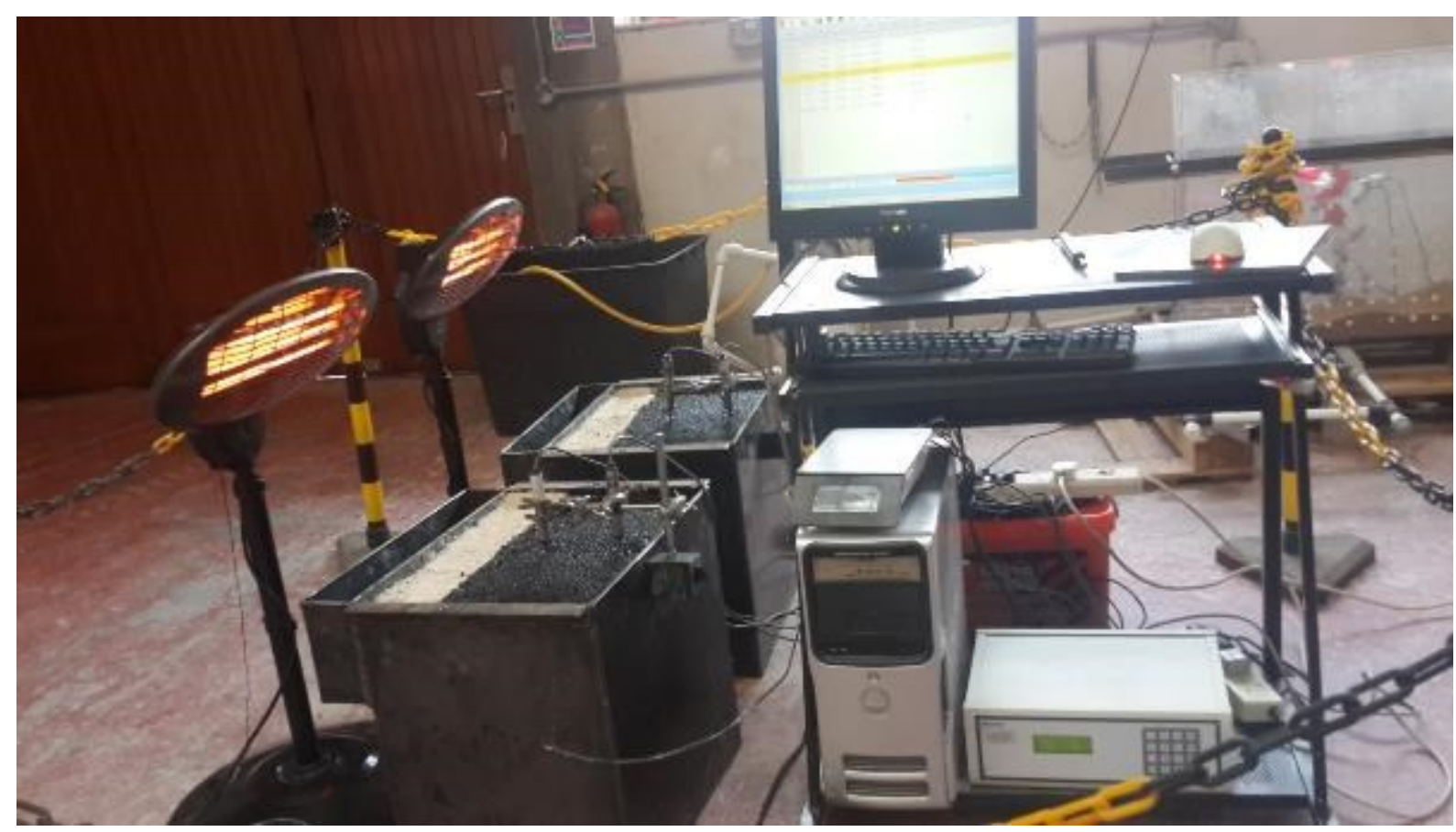

Figure 3 Test in progress where drying period is being simulated by infrared heaters 


\subsection{Materials}

\subsubsection{Clays}

The soils used were kaolin (also known as china clay) and sodium bentonite clays. These are processed soils used to reduce variabilities in natural soils composition and properties. Kaolin and bentonite used in this investigation were supplied by Siberco and Tolsa respectively. Bentonite is an expansive clay soil which is mainly composed of montmorillonite minerals, and kaolin

is a clay soil of low swelling potential which is composed mostly of kaolinite minerals. The two soils were mixed at different proportions to produce an expansive soil of high swelling potential as discussed in section 2.3.1.

\subsubsection{Aggregates base course}

Aggregates material used in the testing program was aggregates MOT type 1 subbase (Travis Perkins, 2019) used in road construction. The maximum dry density (MDD) and optimum moisture content (OMC) of the aggregates base course material determined according to BS 1377-4:1990 are $2180 \mathrm{~kg} / \mathrm{m} 3$ and 4\% respectively. Particle size distribution analysis was conducted according to BS 1377-2:1990, and 100\% of aggregates were found to be finer than $37.5 \mathrm{~mm}$ sieve. The aggregates have coefficient of uniformity $(\mathrm{Cu})$, coefficient of curvature $(\mathrm{Cc})$, and mean particle size d50 of 6; 1.6; and $13.4 \mathrm{~mm}$ respectively. According to Unified Soil Classification System (USCS), the aggregate material is classified as a well-graded gravel GW.

\subsubsection{Cold Lay Macadam}

Ready to use cold lay macadam with $6 \mathrm{~mm}$ graded material was supplied by Wickes. To promote a better adhesion between granular base and cold lay macadam, Hanson road repair bitumen sealer was used. The cold lay macadaxm was compacted at a density of $2100 \mathrm{~kg} / \mathrm{m} 3$.

\subsubsection{Geosynthetics}

Geogrid materials used in the experimental work include E'grid 30/30 supplied by Wrekin Products Ltd, and a non-woven geotextile Terrex NW8 supplied by Abg ltd. The mechanical properties of the geosynthetics are presented in Table 1 and Table 2. 


\subsection{Experimental testing}

As reported by Shumbusho et al. (2020), the high plastic soils $\mathrm{CH}$ tend to be more problematic within the initial first or second wetting and drying cycles experiencing higher amounts of swelling than in the later cycles. To this end, only one drying and one wetting cycle were carried out on reinforced and unreinforced test sections as shown in Table 3. In the reinforced test section, a geogrid was placed at base-subgrade interface.

Table 1 Properties of geogrid E'Grid 30/30

\begin{tabular}{lcc}
\hline \multirow{2}{*}{ Geogrid properties } & \multicolumn{2}{c}{ Value } \\
& MD & XD \\
\hline Aperture size $(\mathrm{mm}$ & 37 & 37 \\
Tensile strength $(\mathrm{kN} / \mathrm{m})$ & 30 & 30 \\
Tensile load at $2 \%$ strain $(\mathrm{kN} / \mathrm{m})$ & 11 & 11 \\
Tensile load at $5 \%$ strain $(\mathrm{kN} / \mathrm{m})$ & 21.6 & 21.6 \\
Junction efficiency $(\%)$ & \multicolumn{2}{c}{$>95$} \\
Radial stiffness $(\mathrm{kN} / \mathrm{m})$ & \multicolumn{2}{c}{550} \\
\cline { 2 - 2 } MD: Machine direction &
\end{tabular}

Table 2 Properties of geotextile Terrex ABG NW8

\begin{tabular}{cc}
\hline Properties & Value \\
\hline Thickness at 2 $\mathrm{kPa}(\mathrm{mm})$ & 1.2 \\
Mass per unit area $(\mathrm{g} / \mathrm{m} 2)$ & 120 \\
Tensile strength $\mathrm{MD} / \mathrm{XD}(\mathrm{kN} / \mathrm{m})$ & $9.5 / 9.5$ \\
Puncture resistance $(\mathrm{N})$ & 1600 \\
Water flow normal to the plane $\left(1 . \mathrm{m}^{2} . \mathrm{s}\right)$ & 105 \\
pore size $(\mu \mathrm{m})$ & 115 \\
Dynamic perforation cone drop $(\mathrm{mm})$ & 32 \\
\hline MD: Machine direction & \\
XD: Cross machine direction
\end{tabular}


Table 3 Cyclic drying and wetting tests

\begin{tabular}{ccccc}
\hline \multicolumn{3}{c}{ Thickness of pavement layers $(\mathrm{cm})$} & Geosynthetic location \\
Tests & Subgrade & Base & Macadam & Control \\
\hline 1 & 25 & 8 & 3 & GG30 at base-subgrade interface \\
2 & 25 & 8 & 3 & GG30: geogrid E'Grid 30/30
\end{tabular}

\subsubsection{Preparation of expansive soil}

Two processed soil materials (kaolin and bentonite) were mixed in different proportions to obtain an expansive soil subgrade of high expansivity. The soil expansivity was estimated by Free swell index (FSI) defined by Indian Standards (IS: 2720 (Part XL) -1977) as follows:

$F S I=\frac{V_{d}-V_{k}}{V_{k}} * 100$

Eq. 1

Where,

FSI: Free swell Index expressed in \%

$V_{d}$ : Equilibrium sediment volume of $10 \mathrm{~g}$ of oven-dried soil measured from a $100 \mathrm{ml}$ graduated cylinder containing distilled water. The soil particles should pass through $425 \mu$ sieve

$V_{d}$ : Equilibrium sediment volume of $10 \mathrm{~g}$ of oven dried soil measured from a $100 \mathrm{ml}$ graduated cylinder containing non-polar liquid such as kerosene or carbon tetrachloride. Soil particles should pass through $425 \mu$ sieve.

Sridharan and Prakash (2000) suggested Free Swell Ratio (FSR) method of predicting soil expansivity which is pretty similar to the FSI proposed by Indian Standards (IS: 2720 (Part XL) 1977), and they also proved that the prediction of soil expansivity using FSR is well correlated with the oedometer method proposed by Seed et al. 1962. The FSR (expressed in \%) was defined as:

$$
F S R=\frac{V_{d}}{V_{k}}
$$


As soil particles take longer period to settle in distilled water to the extent that it can take even about a month (Shumbusho, 2014), addition of $0.025 \mathrm{~g}$ of sodium chloride in distilled water can help to reduce significantly the settling time without affecting the final equilibrium sediment volume (Sridharan and Prakash, 2000). To this end, $0.025 \mathrm{~g}$ of sodium chloride was used in experimental work to speed up the sedimentation process of soil particles in distilled water.

Table 4 shows the prediction of soil expansivity based on FSI, oedometer per cent swell, and FSR. Table 5 shows various soils prepared by mixing kaolin and bentonite at different proportions, and the corresponding expansivity predictions using various methods. It can be observed that the soil D of FSI greater than 100 or FSR greater than 2 falls in the category of expansive soils with high degree of expansion as required by subgrade design criteria. However, as indicated by Shumbusho (2014), free swell tests are not always reliable given the fact that FSI and FSR values can significantly vary with different types of kerosene used, and thus failing to provide the true picture of soil expansivity. To this end, oedometer test was also conducted to provide relatively more reliable soil characterisation in terms of degree of expansion.

Table 4 Prediction of soil expansivity based on FSI, Oedometer per cent swell, and FSR (IS: 2720 (Part XL) -1977; Sridharan and Prakash, 2000)

\begin{tabular}{cccc}
\hline Free Swell Index (\%) & Oedometer expansion (\%) & Free Swell Ratio (\%) & Soil expansivity \\
\hline$<50$ & $0-1.5$ & $\leq 1$ & Negligible \\
& & $1-1.5$ & Low \\
$50-100$ & $1.5-5$ & $1.5-2$ & Moderate \\
$100-200$ & $5-25$ & $2-4$ & High \\
$>200$ & $>25$ & $>4$ & Very high \\
\hline
\end{tabular}

${ }^{\mathrm{a}}$ Method proposed by Seed et al., 1962

Table 5 Expansivity predictions of bentonite and kaolin mixed in various proportions

\begin{tabular}{ccccccc}
\hline Soils & Composition & $\mathrm{V}_{\mathrm{d}}(\mathrm{ml})$ & $\mathrm{V}_{\mathrm{k}}(\mathrm{ml})$ & $\mathrm{FSI}(\%)$ & $\mathrm{FSR}(\%)$ & $\begin{array}{c}\text { Oedometer } \\
\text { percent swell } \\
(\%)^{\mathrm{a}}\end{array}$ \\
\hline $\mathrm{A}$ & $\begin{array}{c}5 \% \text { bentonite }+95 \% \text { kaolin } \\
10 \% \text { bentonite }+90 \%\end{array}$ & 35 & 38 & -7.9 & 0.92 & - \\
$\mathrm{B}$ & $\begin{array}{c}\text { kaolin } \\
\mathrm{C}\end{array}$ & 44 & 35 & 26 & 1.3 & - \\
\hline $\begin{array}{c}15 \% \text { bentonite }+85 \% \\
\text { kaolin }\end{array}$ & 48 & 30 & 60 & 1.6 & - \\
\hline
\end{tabular}




\begin{tabular}{ccccccc}
$\mathrm{D}$ & $\begin{array}{c}20 \% \text { bentonite }+80 \% \\
\text { kaolin }\end{array}$ & 55 & 27 & 104 & 2.03 & 31 \\
\hline \multicolumn{6}{c}{ a Method proposed by Seed et al., 1962}
\end{tabular}

The oedometer percent swell was determined following the method proposed by Seed et al. (1962) (cited in Sridharan and Prakash, 2000). In this method, soil swelling potential is defined as percent swell of a soaked soil sample subjected to a surcharge of $7 \mathrm{kPA}$ in oedometer test after being compacted to the maximum dry density at optimum water content. The soil swell readings were taken until swelling stops (after 7 days). The percent swell of soil D with respect to its initial height was determined to be $31 \%$ and it is also presented in Table 5. As $31 \%$ falls in the range of soils with very high degree of expansivity (see Table 4), it was selected to be used as the expansive soil subgrade in the course of this experimental work. The geotechnical parameters of soil D are presented in Table 6.

Table 6 Geotechnical parameters of the subgrade soil (Soil D)

\begin{tabular}{lcc}
\hline Geotechnical property & Value & Standards \\
\hline Liquid Limit (\%) & 128 & \\
Plastic limit (\%) & 32 & BS 1377-2:1990 \\
Plasticity index (\%) & 96 & \\
Optimum moisture content (\%) & 30 & BS 1377-4:1990 \\
Maximum dry density $\left(\mathrm{kg} / \mathrm{m}^{3}\right)$ & 1430 & \\
Swelling pressure $(\mathrm{kPa})$ at OMC and MDD $(\mathrm{kPa})$ & 62.5 & BS 1377:1990 - Part 5.
\end{tabular}

\subsubsection{Compaction of subgrade soil}

The subgrade soil was prepared by mixing $80 \%$ of kaolin and $20 \%$ of bentonite. They were first mixed dry for about 3 minutes using automatic mixer. After 3 minutes, distilled water (30\% of dry mass i.e. optimum moisture content) was added and mixed for further 40 minutes to ensure homogeneity of the mixed material. After mixing, the mixed soil was transferred into a watertight container and allowed to stand for at least overnight to ensure moisture equilibration as recommended by ASTM D 698-07, BS 1377-1-1990 and BS 1377-2-1990. After this standing period, the subgrade soil was compacted into a test tank using a bespoke dynamic impact compaction equipment to achieve MDD of $1430 \mathrm{~kg} / \mathrm{m} 3$ at $\mathrm{OMC}$ of $30 \%$ in five lifts of $5 \mathrm{~cm}$ each. 
Rwanda Journal of Engineering, Science, Technology and Environment, Volume 4, Issue 1, June 2021

eISSN: 2617-233X | print ISSN: 2617-2321

\subsubsection{Preparation and compaction of base course}

The base course was compacted at optimum water content (4\%) to achieve 92\% of MDD (2180 $\mathrm{kg} / \mathrm{m} 3$ ). The base course was compacted in 2 lifts of $4 \mathrm{~cm}$ each. The base CBR strength was determined using the correlation from dynamic cone penetration test developed by Webster et al. (1992) (Eq. 3) when a $8 \mathrm{~kg}$ hammer is used. The procedure of conducting dynamic cone penetration test is documented in ASTM D6951 / D6951M - 18. The average dynamic cone penetration index (DCPI) was found to be $17 \mathrm{~mm}$ per hammer blow which corresponds to the CBR value of $12 \%$.

$C B R=292 /(D C P I)^{1.12}$

Eq. 3

\subsubsection{Calibration of 5TM moisture sensors}

Initially, it was intended to use at least five 5TM moisture sensors in a test tank to be able to monitor moisture changes at multiple locations of the subgrade. However, the trial tests showed that because of the limited size of the test tank, the sensors interfered between themselves thereby affecting substantially the recorded moisture data. In order to minimize their interference, only two moisture sensors were adopted to be used in a test tank to monitor moisture changes of the subgrade. The moisture monitoring set up manufactured by Meter Group was made of ZL6 data logger that uses Zentra utility software to log moisture and temperature data of the subgrade, and two 5TM moisture sensors.

The moisture sensors were designed to record moisture content expressed in volumetric water content (VWC). To convert VWC into gravimetric water content (GWC), Eq. 4 was used. As the recorded VWC were not reflecting the real moisture of the subgrade, it was necessary to calibrate the moisture sensors for the expansive soil subgrade used. The calibration process was adopted based on manufacturer recommendations for performing soil-specific calibration (Meter Group, 2017). Throughout calibration process, it was observed that the recorded subgrade moisture data was significantly affected by the change in temperature. For example for the same GWC of the soil, VWC could change from 60 to $100 \%$ when temperature changes from 20 to $30^{\circ} \mathrm{C}$. To this end, the analysis of the recorded data took account for the effect of temperature change during testing process. The reference was taken at $20^{\circ} \mathrm{C}$ where corresponding VWC readings over the testing period were determined and used to work out their equivalent GWC. 
$G W C=\frac{V W C}{D D}$

Where,

GWC: Gravimetric water content (expressed in \%)

VWC: Volumetric water content (expressed in \%)

DD: Dry density of the soil (dimensionless)

2.4 Long time monitoring of expansive soil material compacted in CBR moulds.

Four soil samples of soil D were compacted at OMC and MDD in CBR moulds (BS 1377-4:1990) and were immersed in water for 7 days. The moulds had perforated base that allowed ingress of water from bottom up. The soil specimens were subjected to a surcharge of $4 \mathrm{~kg}$ using two discs of $2 \mathrm{~kg}$ each (see BS 1377-4:1990) to simulate field surcharge of about $11 \mathrm{~cm}$ thickness as presented in Figure 2. After 7 days, they were partially dried out in oven at $40^{\circ} \mathrm{C}$ for 3 days. Figure 4 illustrates a typical soil specimen after being partially dried. After being dried, they were reimmersed in water and allowed to stand there for up to a period of 11 months to monitor their swelling behaviour. Figure 5 illustrates the swelled soil specimens after standing in a water tank for 11 months. The recorded swelling data were compared to the oedometer percent swell to find out how well the oedometer test could predict the swelling behaviour of compacted expansive soil.
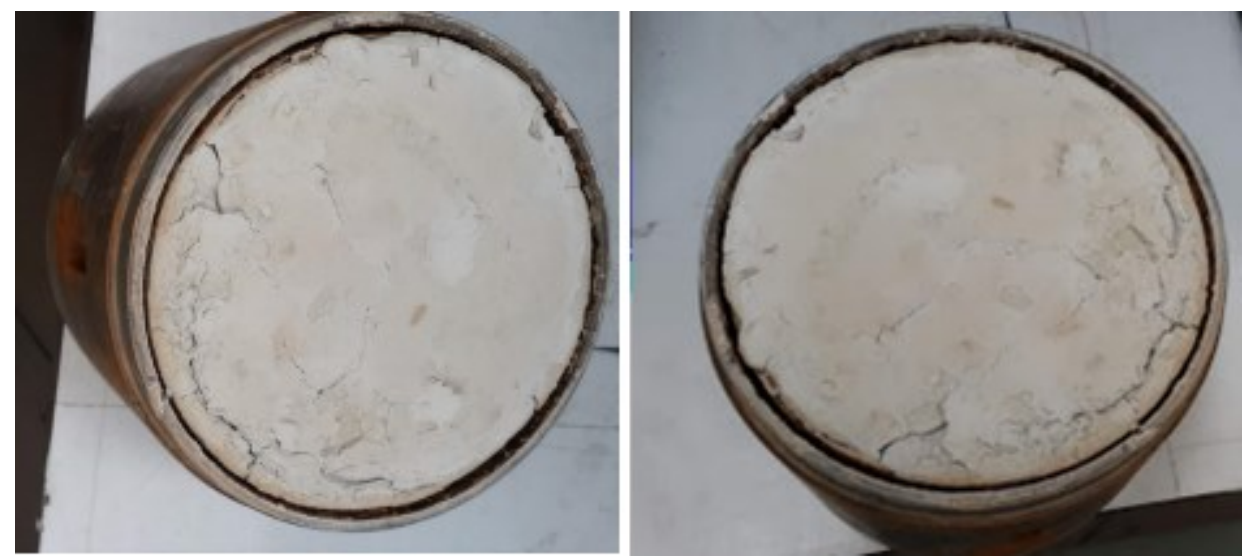

Figure 4 Typical compacted soil specimen after 3 days of drying at $40^{\circ} \mathrm{C}$ 


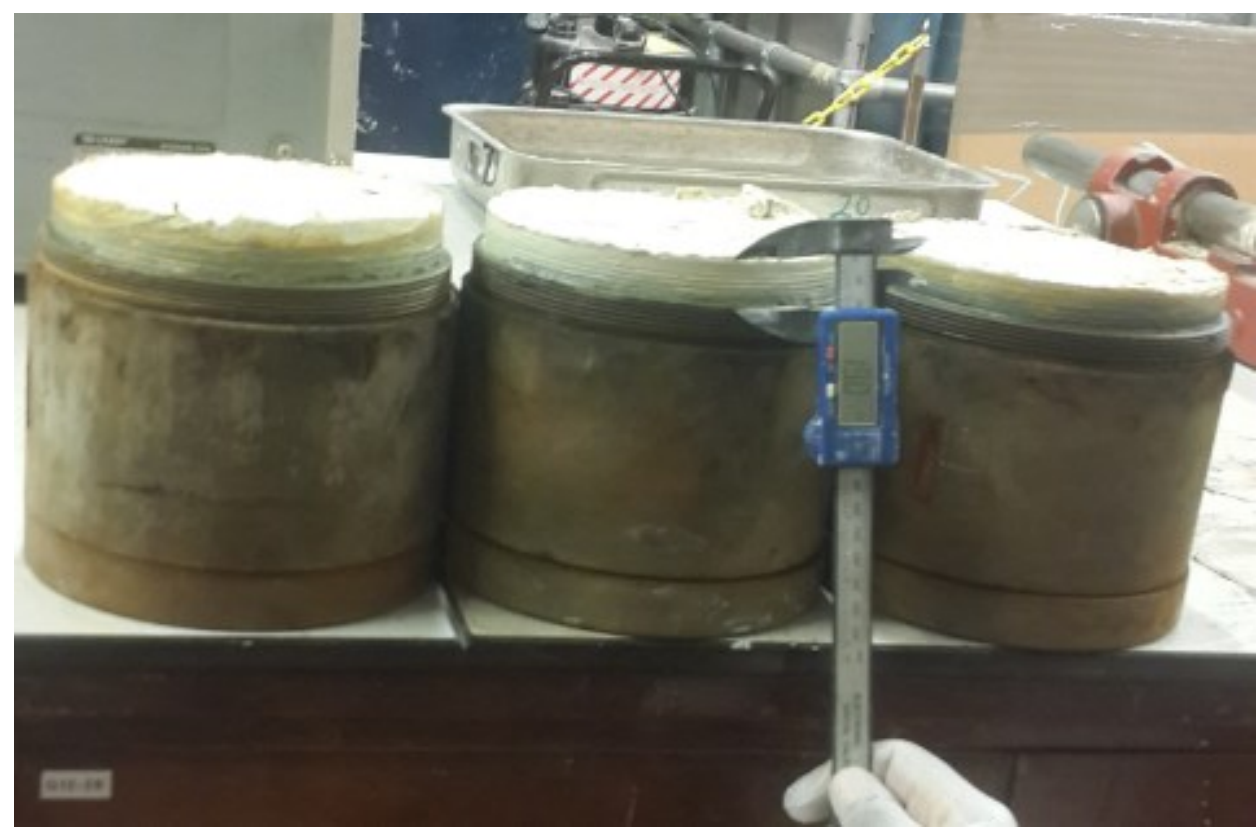

Figure 5 Swelled soil specimens after a 11 month period in a water tank

\section{Experimental results and discussion.}

\subsection{Compacted soil specimens in CBR moulds}

The details about preparation and monitoring of compacted expansive soil material in CBR moulds are presented in section 2.4. The average swell amounts and percent swell of soil specimens compacted in CBR moulds are presented in Table 7. The latter was calculated with respect to the initial height of soil specimen (height of CBR mould) which was $127 \mathrm{~mm}$.

Table 7 Average swell amounts and percent swell of soil specimens compacted in CBR moulds

\begin{tabular}{c|c|c|c}
\hline $\begin{array}{c}\text { Reference with respect } \\
\text { to drying phase }\end{array}$ & $\begin{array}{c}\text { Soaking } \\
\text { period }\end{array}$ & $\begin{array}{c}\text { Average swell amounts } \\
(\mathrm{mm})\end{array}$ & $\begin{array}{c}\text { Average Percent } \\
\text { swell (\%) }\end{array}$ \\
\hline Before partial drying & 7 days & 2.7 & 2.1 \\
\hline \multirow{3}{*}{ After partial drying } & 7 days & 3.8 & 3 \\
\cline { 2 - 4 } & 6 weeks & 12.5 & 10 \\
\cline { 2 - 4 } & 11 months & 20 & 15.7 \\
\hline
\end{tabular}

As it can be seen from Table 7, average swell amount at 7 days soaking period after partial drying is more than the swell amount at 7 days soaking period before the drying phase. This is due to the 
Rwanda Journal of Engineering, Science, Technology and Environment, Volume 4, Issue 1, June 2021

eISSN: 2617-233X | print ISSN: 2617-2321

fact that cracks developed during drying period increased soil permeability, which in turn increased water absorption and rate of soil swelling.

As presented in section 2.3.1, it was found that oedometer percent swell of the expansive soil (soil D) used in experimental work was 31\%. As shown in Table 7, the percent swell $(15.7 \%)$ determined over 11 months period is remarkably less than that found using oedometer. In addition, as the oedometer soil swell was determined over a period of 7 days, the percent swell of soil specimens in CBR moulds after 7 days soaking period in comparison to oedometer percent swell is even far lower. This suggests that laboratory oedometer swell overpredicts the in-situ soil swell of expansive soils as reported by Lytton et al. (2004). Taking two extremes of percent swell corresponding to 7 days and 11 months (3\% and $15.7 \%$ respectively) from Table 7 , it can be argued that oedometer percent swell (31\%) overpredicts in-situ soil swelling by a factor ranging between 2 and 10 depending upon the period over which an expansive soil has been in contact with water.

When swelling information of a potential expansive soil is needed along with its soaked CBR value, BS 1377-4:1990 recommend soaking the soil specimen in CBR mould for 4 days and record the swell data. They also mention that soaking period may be extended to allow swelling process to complete. Based on the experimental results of this study, it was found that after 4 days soaking period, there was no appreciable swell and only swell amount as low as $2 \mathrm{~mm}$ was recorded. This suggests that for expansive soils of high plasticity, 4 days soaking period is not long enough to provide a reasonable indication of soil swelling behaviour. Nevertheless, when a 4 days soaking period reflects wetting conditions of the field under consideration, soaking soil specimens in CBR mould for that long may provide a sensible prediction of in-situ soil swell. In such circumstances, the results determined from laboratory oedometer test would even further overpredict the swelling behaviour of the real field conditions.

\subsection{Effects of drying period on pavement sections built over expansive soil}

After a 35 days drying period, data recorded by 5TM moisture sensors embedded at a depth of 16 $\mathrm{cm}$ from pavement surface (see Figure 1) showed that the gravimetric water content of the subgrade around the probes reduced only by as little as $1 \%$. As the moisture probes were embedded fairly deep, such an observation is in agreement with Greve et al. (2010) who after drying a 
cracking soil dominated by montmorillonite clay for up to 84 days found that the change in anisotropy index (homogeneity parameter which is related to soil moisture) occurred mostly within upper $10 \mathrm{~cm}$ and was relatively constant below that depth i.e moisture content at depths deeper than $10 \mathrm{~cm}$ was not likely to be affected by the drying period.

After the drying period, there were no cracks observed on any of the pavement sections. The shrinking deformation recorded using LVDTs on both pavements during drying period is presented in Figure 6. LVDT 1 and LVDT 2 were used on unreinforced section where the former was closer to pavement shoulder and the latter was closer to the assumed longitudinal centerline. Equally, LVDT 3 and LVDT 4 were used on reinforced section where the former was closer to shoulder and the latter was closer to the longitudinal centerline as presented in Figure 2. As it would be expected, the LVDTs placed closer to pavement shoulders experienced higher vertical shrinking deformation in comparison to those placed closer to the longitudinal centerline. The recorded vertical shrinking deformation data suggest that the differential shrinking movement across unreinforced section is larger than the one across reinforced section. This is illustrated in Figure 6 where the difference in measured deformation (a) between LVDTs placed across unreinforced section is two times larger than that (b) of LVDTs placed across reinforced section.

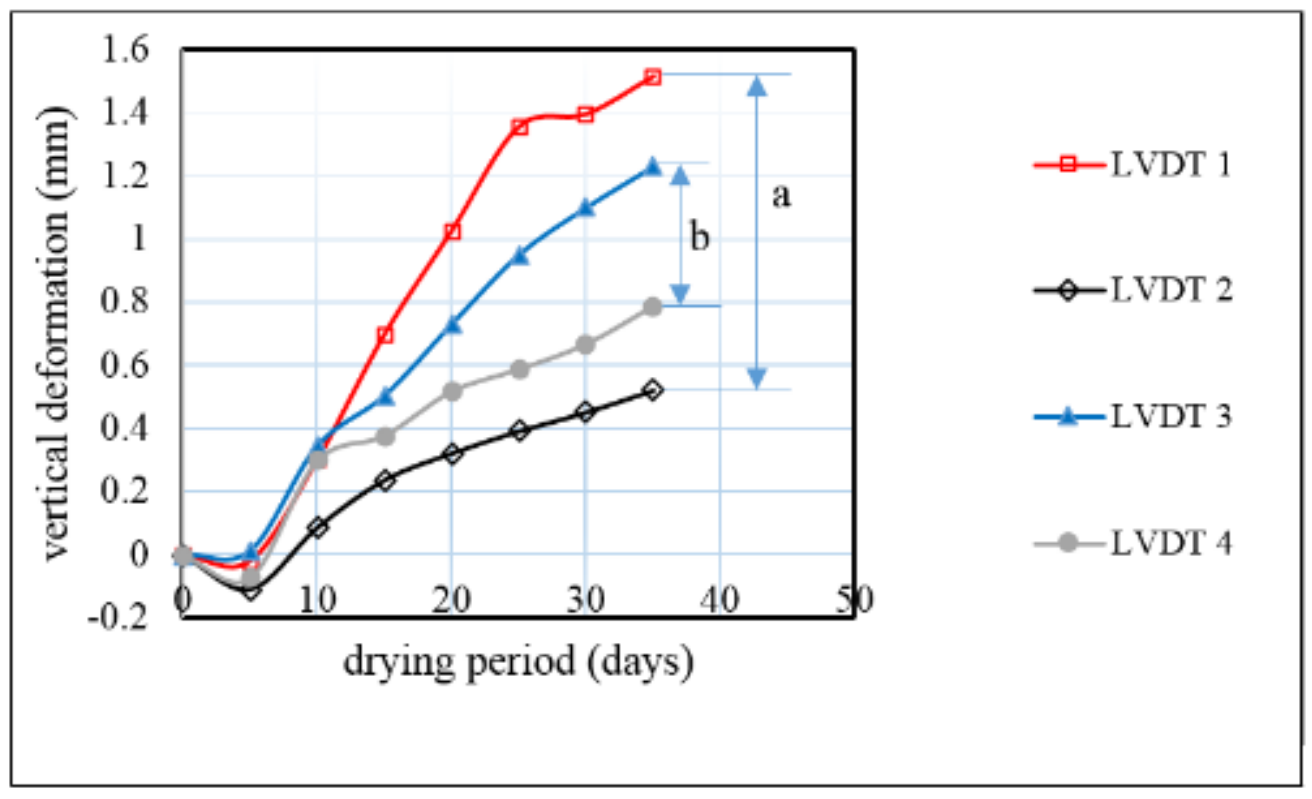

Figure 6 Vertical shrinking deformation on pavement test sections 
Although vertical shrinking deformation on pavements built over expansive soil is apparent as shown in Figure 6, lateral shrinking deformation appears to be the one of more concern. The observation of pavement sections after drying period showed that the bulk volume of expansive soil material shrunk laterally retracting itself from the plane of anisotropy considered to be the weakness plane as far as tensile resistance is concerned. As shown in Figure 7, subgrade material at pavement shoulders got detached from the walls of the test tank leaving out voids $\mathrm{A}, \mathrm{B}$, and $\mathrm{C}$. Table 8 shows the width and depth of voids left out by clay retraction from the walls of test tanks for both reinforced and unreinforced sections. Equally, as presented in Figure 4, the dried clay material shrunk laterally getting detached from the walls of CBR moulds. Given the dimensions of the test tank, it appears that it is of small size to the extent that longitudinal cracks may not develop along the pavement. This is explained by the fact that the width of the pavement shoulders $(10 \mathrm{~cm}$ ) is too small to undergo appreciable lateral movements (only 1 to $2 \mathrm{~mm}$ detachment was observed). On the other hand, because of relatively larger component of pavement shoulders in longitudinal direction $(45 \mathrm{~cm})$, the clay material was more likely to experience larger lateral movements in that direction, and consequently leaving out wider voids ( 5 to $7 \mathrm{~mm}$ ) from the walls of test tank crosswise (see Figure 7 and Table 8) and cross sectional cracks (see Figure 8). Such an observation indicates that significant level of cracking or clay retraction along an anisotropy plane takes place in opportunistic direction (defined by the directional size of clay material lengthwise or widthwise, and the location of nearby anisotropy plane), and the cracks/retraction develop perpendicularly to the direction of lateral movements. Assuming pavement shoulders of sufficient width (where appreciable lateral movements would take place), upon very long dry period, the subgrade moisture would reduce progressively towards pavement longitudinal centerline which is covered and less prone to moisture fluctuation (Zornberg and Gupta, 2009), and at some point [such as for example when variation of the monthly gravimetric water content exceeds $20 \%$, monthly average moisture content drops to less than $15 \%$ for a period of more than 1 month, and the gravimetric suction exceeds $1500 \mathrm{kPa}$ during dry season (Puppala et al., 2011)], the longitudinal cracking may initiate. The longitudinal cracking initiation can be thought to be a result of lateral retraction of expansive soil bulk volume along the longitudinal anisotropy plane at interface of two soil compartments of different moisture contents (the drier compartment produced by progression of shoulder edge effects during dry period and the wetter compartment closer to 
pavement centerline) comparably to the retraction from the anisotropy plane at interface of compacted clay material and the walls of test tank.

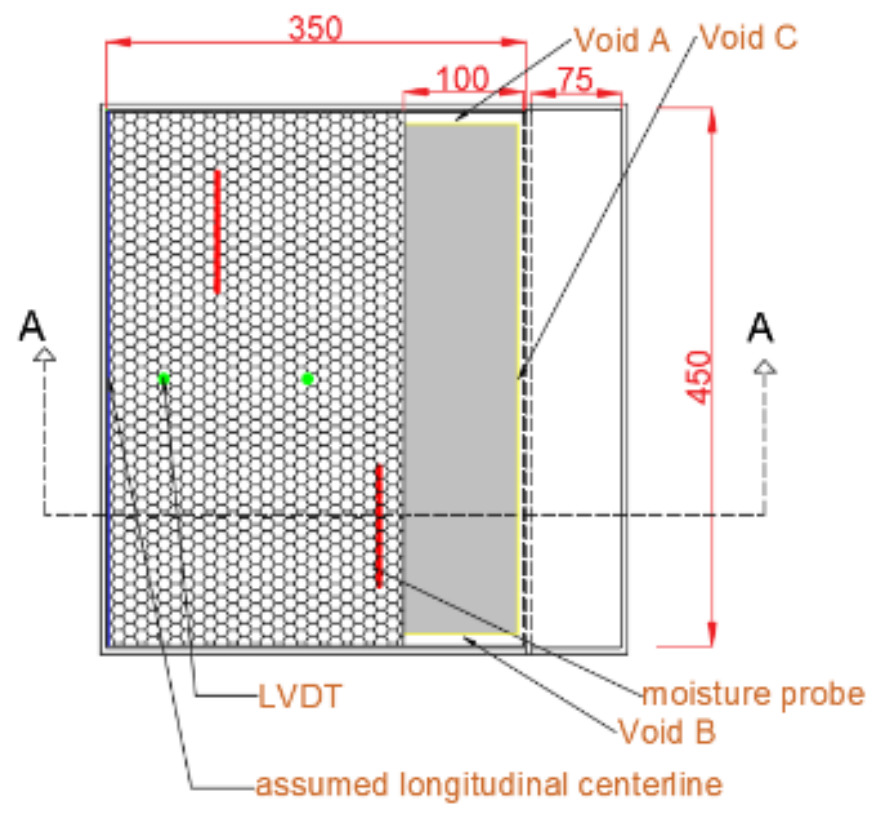

Figure 7 Plan view of the experiment illustrating voids left out by lateral retraction of clay material from the tank walls

Table 8 Dimensions of voids left out by clay retraction from the walls of test tank

\begin{tabular}{lcccccc}
\hline & \multicolumn{2}{c}{ Void A } & \multicolumn{2}{c}{ Void B } & \multicolumn{2}{c}{ Void C } \\
& Reinforced & Unreinforced & Reinforced & Unreinforced & Reinforced & Unreinforced \\
\hline Width $(\mathrm{mm})$ & 5 & 7 & 5 & 5 & 1 & 2 \\
Depth $(\mathrm{mm})$ & 9 & 11 & 8.5 & 10 & - & 10 \\
\hline
\end{tabular}




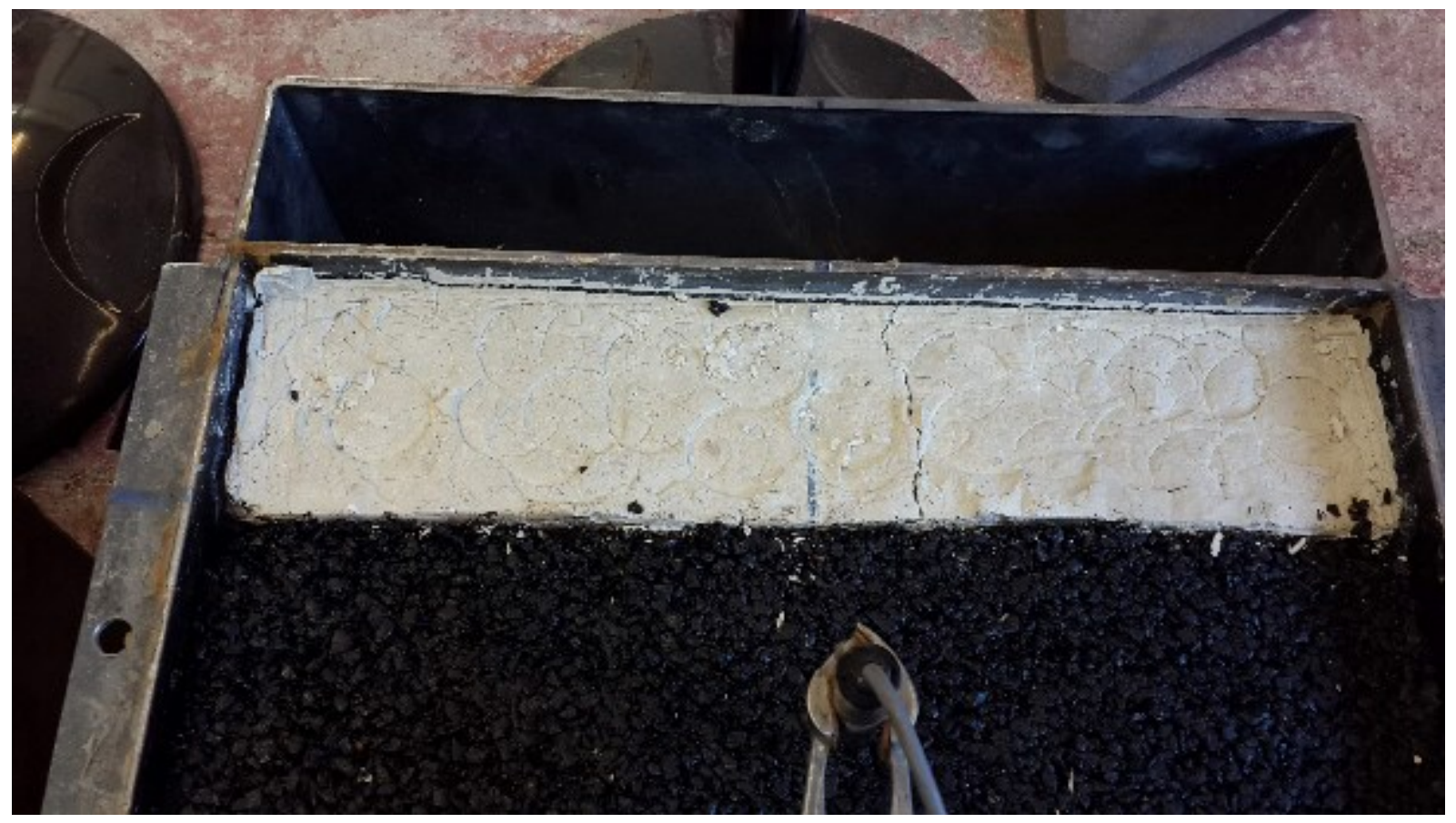

Figure 8 Illustration of a cross sectional crack on shoulder of a test section

\subsection{Effects of wetting period on experimental pavement test sections built over expansive soils}

The test sections were wetted for a period of 50 days as explained in section 2.1. Three moisture probes installed in the subgrade below test sections showed approximately similar water contents of about $34 \%$ and $36.5 \%$ after 25 and 50 days respectively, which indicate a significant increase in water content with respect to the initial compaction moisture content (30\%). The fourth moisture probe appeared to malfunction and its moisture content readings are not herein presented. The swelling deformation data recorded by LVDTs over a period of 50 days are presented in Figure 9. It can be observed that LVDT 1 and LVDT 3 placed closer to the shoulders of unreinforced and reinforced sections respectively recorded the highest swell deformations. These observations appear to be in agreement with Nelson and Miller (1992) and Zornberg and Gupta (2009) that during wet seasons, heave develops in the vicinity of pavement shoulders but not close to the centerline because of moisture increase near pavement edges. Visual observation and the recorded swell deformation data showed that the differential swelling movement across unreinforced section was larger than across reinforced section. This can be illustrated in Figure 9 where the difference 
in measured deformation (a) between LVDTs placed across unreinforced section is three times larger than that (b) of LVDTs placed across reinforced section. It is possible that geogrid in a reinforced section may have distributed swelling stresses allowing a more uniform swelling rather than a differential swell responsible for development of surface roughness.

The highest swelling deformation recorded on test section after 50 days wetting period is nearly $16 \mathrm{~mm}$. This amounts to a percent swell of $6.4 \%$ with respect to the initial thickness of clay layer $(25 \mathrm{~cm})$. In comparison to the oedometer percent swell $(31 \%)$ determined after 7 days wetting period, it is clear that oedometer test can overpredict swell behaviour of expansive soil as presented in section 3.1 .

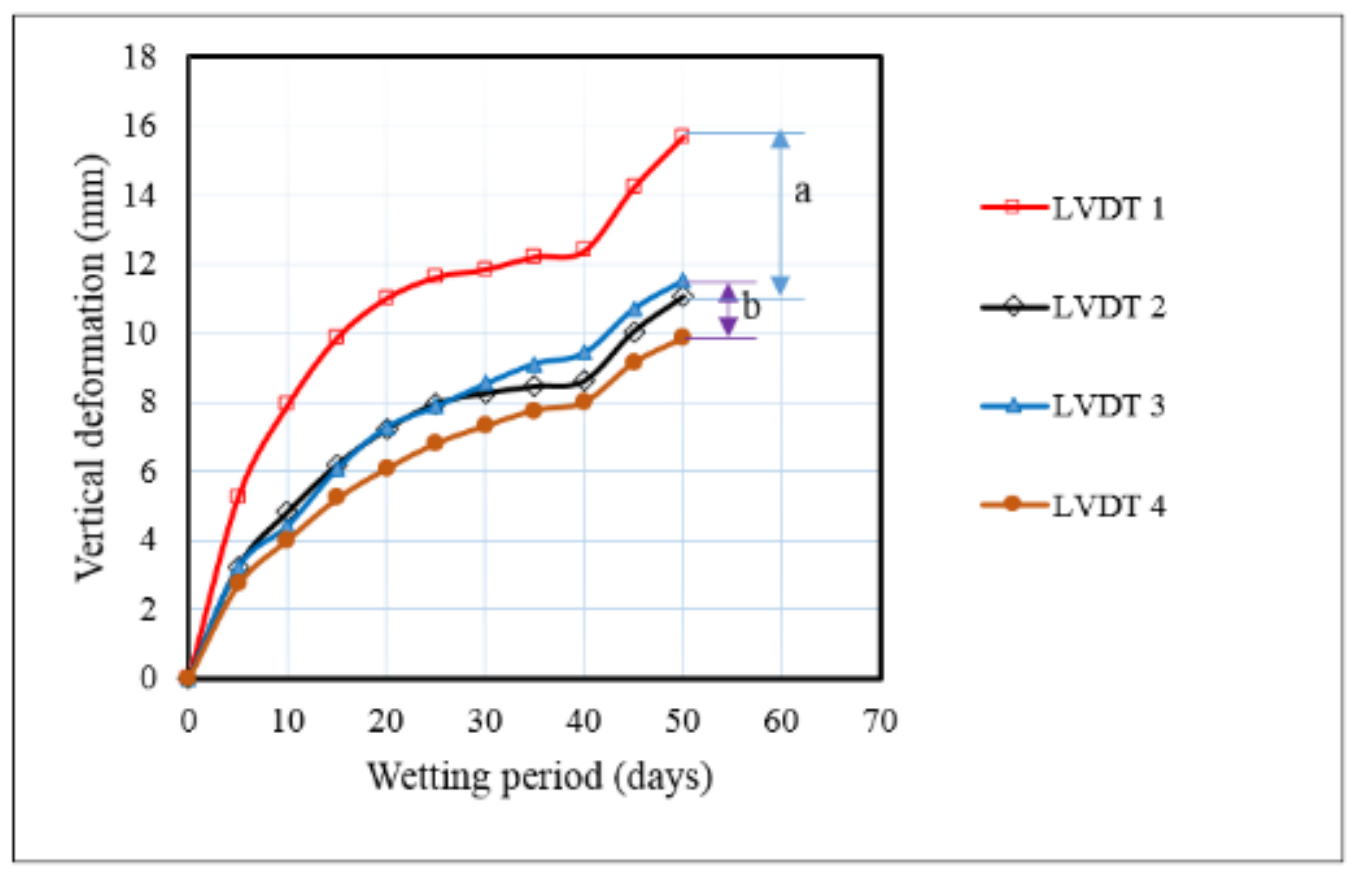

Figure 9 swelling deformation of test sections

The fact that in both drying and wetting period the reinforced test section experienced less differential deformation in comparison to unreinforced section appears to support the findings of field studies conducted by Zornberg et al. (2012) and Dessouky et al. (2015) where reinforced pavement sections presented lesser defects in comparison to unreinforced sections after a monitoring period of up to 6 years. 
Rwanda Journal of Engineering, Science, Technology and Environment, Volume 4, Issue 1, June 2021

eISSN: 2617-233X | print ISSN: 2617-2321

\section{Conclusions}

The main objective of this study was the evaluation of using geogrids in mitigating pavement defects on roads built over expansive soils. Following an experimental work conducted to investigate the shrink/swell effects of expansive soil subgrades on overlying pavements, below are conclusions:

1. The experimental work showed that oedometer percent swell overpredicts in-situ swell behaviour of expansive soils. The oedometer percent swell (conducted over a period of 7 days) of the expansive soil used in experimental work was 31\%; it was found to be twice higher than the percent swell of the same soil compacted in CBR moulds and soaked in water for a period of 11 months. In addition, as the oedometer swell was determined over a period of 7 days, the percent swell of soil specimens in CBR moulds after 7 days soaking period in comparison to oedometer percent swell was found to be far lower (3\%). Taking the recorded percent swell after 7 days and 11 months (i.e. 3 and $15.7 \%$ respectively), it was found that oedometer percent swell (31\%) can overpredict in-situ swelling behaviour of the expansive soil under consideration by a factor ranging between 2 and 10 depending upon the period (ranging between 7 days and 11 months) over which the expansive soil has been in contact with water.

2. The recorded vertical shrinking deformation data showed that the differential shrinking movement across unreinforced section was twice larger than across reinforced section, thus suggesting the effect of geogrid on alleviating differential shrinking movement of pavements built over expansive soils.

3. Visual observation and the recorded swell deformation data showed that the differential swelling movement across unreinforced section was three times larger than across reinforced section, thus suggesting the beneficial effect of geogrid reinforcement in alleviating the development of roughness on pavements built over expansive soils. The highest swelling deformation recorded on test section after 50 days wetting period was nearly $16 \mathrm{~mm}$ which amounted to a percent swell of $6.4 \%$ with respect to the initial thickness of the subgrade layer $(25 \mathrm{~cm})$. In comparison to the oedometer percent swell (31\%), the swell behaviour of the pavement over expansive soil has been overestimated by a factor of 5 when considering a wetting period of 50 days. 
Rwanda Journal of Engineering, Science, Technology and Environment, Volume 4, Issue 1, June 2021

eISSN: 2617-233X | print ISSN: 2617-2321

4. Given the fact that the test tank for investigation of shrink/swell effects of expansive soils on pavements was too small to allow significant lateral movements of expansive soils, it is recommended to carry out further research using test tanks of sufficient size and allowing the time long enough to investigate the mechanism of formation of longitudinal cracks. Geophysical method such as Electrical Resistivity Tomography (ERT) to monitor onset and progression of cracks would also be recommended. 
Rwanda Journal of Engineering, Science, Technology and Environment, Volume 4, Issue 1, June 2021

eISSN: 2617-233X | print ISSN: 2617-2321

\section{References}

ASTM Standard D698-07, 2007, Standard Test Methods for Laboratory Compaction

Characteristics of Soil Using Standard Effort (12 $400 \mathrm{ft}-\mathrm{lbf} / \mathrm{ft} 3(600 \mathrm{kN}-\mathrm{m} / \mathrm{m} 3))$, ASTM International, West Conshohocken, PA.

ASTM Standard D6951 / D6951M - 18, 2018, Standard Test Method for Use of the Dynamic Cone Penetrometer in Shallow Pavement Applications, ASTM International, West Conshohocken, PA.

BS 1377-1:1990, 1990, Methods of test for soils for civil engineering purposes. General requirements and sample preparation, British Standard Institute, London

BS 1377-2:1990, 1990, Classification tests, British Standard Institute, London

BS 1377-4:1990, 1990, Soils for civil engineering purposes - compaction related tests, British Standard Institute, London

BS 1377-5:1990, Methods of test for soils for civil engineering purposes. Compressibility, permeability and durability tests, British Standard Institute, London

Bureau of Indian standards (1978). IS: 2720 (Part XL)-1978. Determination of free swell index of soils. New Delhi, India

Chen, F. H. (1975), Foundations on Expansive Soils, Elsevier Scientific Publishing Company, Amsterdam, Holland

Dessouky, S. H., 2015, Pavement repairs long-term performance over expansive soil: IFCEE 2015. International Foundations Congress and Equipment Expo 2015, 17-21 March 2015, p. 380-7.

Dessouky, S. H., J. Oh, M. Ilias, S. I. Lee, and D. Park, 2015a, Investigation of Various Pavement Repairs in Low-Volume Roads over Expansive Soil: Journal of Performance of Constructed Facilities, v. 29, p. 9.

Greve, A. K., R. I. Acworth, and B. F. Kelly, 2010, Detection of subsurface soil cracks by vertical anisotropy profiles of apparent electrical resistivity: Geophysics, v. 75, p. WA85WA93

Jeyapalan, J. K., G. T. Rice, and R. L. Lytton, 1981, State-of-the-art Review of Expansive Soil Treatment Methods, Texas A \& M University. 
Jones, Lee D. and I. Jefferson (2012), Expansive soils. In: Burland, J., (ed.) ICE manual of geotechnical engineering, Volume 1, geotechnical engineering principles, problematic soils and site investigation. London, UK, ICE

Luo, R., and J. A. Prozzi, 2009, Combining Geogrid Reinforcement and Lime Treatment to Control Dry Land Longitudinal Cracking: Transportation Research Record, p. 88-96.

Luo, R., and J. A. Prozzi, 2010, Development of Longitudinal Cracks on Pavement over Shrinking Expansive Subgrade: Road Materials and Pavement Design, v. 11, p. 807-832.

Lytton, R., C. Aubeny, and R. Bulut, 2004, Design procedure for pavements on expansive soils: volume, report No. FHWA/TX-05-518-1, 95-10. Texas Transportation Institute.

Meter Group, 2017, Soil-specific calibrations for METER soil moisture sensors, https://www.metergroup.com/environment/articles/method-a-soil-specific-calibrationsfor-meter-soil-moisture-sensors/, accessed on 10 ${ }^{\text {th }}$ March 2019.

Mokhtari, M. and Dehghani, M. (2012), Swell-Shrink Behavior of Expansive Soils, Damage and Control, EJGE. Vol.17

Nelson, J. D., and D. J. Miller, 1992, Expansive soils: Problems and practice in foundation and pavement engineering, p. 260.

Petry, T. M., and D. N. Little, 2002, Review of stabilization of clays and expansive soils in pavements and lightly loaded structures - History, practice, and future: Journal of Materials in Civil Engineering, v. 14, p. 447-460.

Picornell, M., and R. L. Lytton, 1987, BEHAVIOR AND DESIGN OF VERTICAL MOISTURE BARRIERS: Transportation Research Record, p. 71-81.

Puppala, A. J., T. Manosuthkij, S. Nazarian, and L. R. Hoyos, 2011, Threshold moisture content and matric suction potentials in expansive clays prior to initiation of cracking in pavements: Canadian Geotechnical Journal, v. 48, p. 519-531.

Scullion, T., Guthrie, S. and Sebesta S., (2003), Field performance and design recommendations for full depth recycling in Texas, FHWA/TX-03/4182-1, Texas

Sebesta, S., 2002, Investigation of maintenance base repairs over expansive soils: Year 1 report, Texas Transportation Institute, Texas A \& M University System.

Seed, H. B., Woodward R. J., and Lundgren R, Prediction of swelling potential for compacted clays, 1962, Journal of the Soil Mechanics and Foundations Division, ASCE, 88, No. SM3, 53-87 
Shumbusho, R., 2014, Utilization of pulverised fuel ash to reduce shrink-swell characteristics of expansive soils, Thesis (Msc.), University of Birmingham, Birmingham, UK

Shumbusho, R., Ghataora, G. and Burrow, M.P., 2018, The mitigation of longitudinal cracks on low-volume road pavements built over expansive soils. 2018 IRF/SARF/PIARC Regional conference for Africa. Durban, 9th - 11th October 2018

Shumbusho, R., Ghataora, G., Burrow, M.P., and Rwabuhungu, D., 2020, Advances in cyclic shrink and swell behaviour of expansive soils. Unpublished manuscript

Sridharan, A. and Prakash, K. (2000). Classification procedures for expansive soils. Geotech. Engineering, 235-240-Paper 12075

Travis Perkins, 2019, MOT type 1 sub-base, https:/www.travisperkins.co.uk/bagged-sand-andaggregates/mot-type-1-sub-base-bulk-bag/p/938251

Tripathy, S., K. S. S. Rao, and D. G. Fredlund, 2002, Water content - void ratio swell-shrink paths of compacted expansive soils: Canadian Geotechnical Journal, v. 39, p. 938-959.

Wanyan, Y., I. Abdallah, S. Nazarian, and A. J. Puppala, 2010, Expert System for Design of Low-Volume Roads over Expansive Soils: Transportation Research Record, p. 81-90.

Webster, S.L., Grau, R.H., Williams, R.R., 1992, Description and Application of Dual Mass Dynamic Cone Penetrometer, U.S. Army Engineer Waterways Experiment Station, Instruction Report, No. GL-92 e3.

Zornberg, J. G., and R. Gupta, 2009, Reinforcement of pavements over expansive clay subgrades: 17th International Conference on Soil Mechanics and Geotechnical Engineering, ICSMGE 2009, October 5, 2009 - October 9, 2009, p. 765-768.

Zornberg, J., G. Roodi, J. Ferreira, and R. Gupta, 2012, Monitoring Performance of Geosynthetic-Reinforced and Lime-Treated Low-Volume Roads under Traffic Loading and Environmental Conditions, GeoCongress 2012, American Society of Civil Engineers, p. $1310-1319$. 